\title{
INNOVATION PERFORMANCE OF ORGANIZATION
}

Globalization has confirmed that the competitive ability of organizations is conditioned by the successful development of innovations. Innovation management and development of innovative potential of organizations are becoming a scientific problem, since the existing approaches in this area do not have satisfactory results. The paper presents a new approach to enhancing innovation performance of the organization that is built on a systematic examination of possible innovation potential of the organization and purposeful creation of a suitable innovative environment in the organization.

Keywords: Innovative potential, innovation performance, market, organization, innovation.

\section{Introduction}

Quality of decision-making depends on the degree of knowledge of causal relations. Deciding on new products, services as well as the development and implementation of new systems is associated with the uncertainty and risk. It may be minimized if we can correctly estimate the consequences and affect the causes of controlled processes. However, this requires the design and use of scientific method for the systematic examination of causation and purposeful search, quantification and increasing the innovation potential in the organization. Only then we can expect a successful commercialization of innovation and success with the customer.

On the one hand, the system identification and quantification of the innovation potential of the organization and, on the other hand, creating an appropriate (innovative) environment in the organization is needed for the successful implementation of this process. We need the environment that will systematically create conditions for the generation, development and commercialization of innovations.

\section{Innovative potential in the organization}

Innovative organizational performance is contingent upon the development of its innovative potential. The significant problem in the organization is the question on how to identify it and subsequently quantify it.

In general, the potential characterizes the extent of opportunities of the object under examination which are available to achieve the desired effect. We understand the desired effect as a transformation from the existing state (IS) to the target state (WILL BE). In relation to the need for creating and commercializing innovation it is necessary to distinguish:

1. Innovative potential of the product. Products and services are marketable products of human labor, which must be capable of fulfilling the requirements of a potential customer. That is why the first natural object of examination is the product.

2. Innovative potential of people. Carriers of the ability to invent, develop and implement new products are people. Therefore, another object of the study is a human (humanity).

3. Innovative potential of the organization. For creating innovation and its commercialization, it is necessary to obtain tangible and intangible resources. Usually the working environment of the organization is the environment that allows you to connect the innovative potential of individuals and working groups with innovation potential of knowledge networks.

In the following sections are highlighted differences of innovative potential of the product, innovative potential of people forming those innovations and innovation potential of the organization.

\section{A. Innovative potential of the product}

Global markets require targeted creating of specific products. We are asking how the offered product suits the specific environment (customer) and what is expected of the product to succeed. Just to answer these questions, the innovative potential of the product $\left(\mathrm{IP}_{\mathrm{PR}}\right)$ must be examined. From a systemic perspective, it is important to opt for such methodologies that continuously assess the potential because it is a newly created tradable product, economically efficient, environmentally

\footnotetext{
* Branislav Micieta, Martin Gaso, Martin Krajcovic

Department of Industrial Engineering, Faculty of Mechanical Engineering, University of Zilina, Slovakia

E-mail: kpi@fstroj.uniza.sk
} 
friendly, ready to be produced, corresponding to the legislation and acceptable for people. In connection to this, it is needed to parametrize these conditions for success.

During the innovation projects, innovator must maximize the innovation potential of the product offered by maximizing the following parameters: marketability $\left(\mathrm{p}_{1}\right)$, economic efficiency $\left(p_{2}\right)$, environmental friendliness $\left(p_{3}\right)$, technology $\left(p_{4}\right)$, legislation $\left(\mathrm{p}_{5}\right)$, and culturalism $\left(\mathrm{p}_{6}\right)$.

$\max \mathrm{IP}_{\mathrm{PR}}=\max \mathrm{f}\left(\mathrm{p}_{1}, \mathrm{p}_{2}, \mathrm{p}_{3}, \mathrm{p}_{4}, \mathrm{p}_{5}, \mathrm{p}_{6}\right)$

while : $p_{1}>0 \wedge p_{2}>0 \wedge p_{3}>0 \wedge p_{4}>0 \wedge p_{5}>0 \wedge p_{6}>0$

By setting the evaluation criteria for $\mathrm{p}_{1-6}$, it is possible to guide the decision already in solving the subtasks of the innovative project.

Innovative potential of the product is the characteristics of the product, which through these parameters expresses its possible commercialization. Innovative potential of the product can be increased by aligning its parameters with the anticipated market requirements. The condition is that none of the product's parameters is in a direct violation of the anticipated market requirements.

As we see, we can assess the potential success of innovation through the key parameters that affect the global market. It is fundamentally a new view eliminating subjective quantification of the strengths and weaknesses of the product.

\section{a. Innovative potential of people}

Innovative potential of people (individuals, groups, humankind) refers to the possibility to invent, develop and implement a product that succeeds with customers. The need to invent is associated with creativity. Creativity means a set of characteristics that gives humans the ability to create a new product or a new process due to changes in human consciousness. Knowledge of the development of creativity allows for the results of scientific investigations in the field of psychology, medicine and management. Knowledge, that every creative individual is a carrier of innovation potential, is essential for studying the innovation potential of people. Innovative potential of an individual can be expressed as a function of three parameters $i_{1-3}$.

$\mathrm{IP}_{\mathrm{I}}=\mathrm{f}\left(\mathrm{i}_{1}, \mathrm{i}_{2}, \mathrm{i}_{3}\right)$

while: $i_{1}>0 \wedge i_{2}>0 \wedge i_{3}>0$

where:

$\mathrm{IP}_{\mathrm{I}}$ innovative potential of individual, $i_{1}$ motivation of the individual, his ability and willingness to cooperate, his personal interest for achieving the objective, courage and desire or need to create something new,

$\mathrm{i}_{2}$ explicit and tacit knowledge of the individual,

$\mathrm{i}_{3}$ working environment.

Innovative potential of defined group of people is formed by contributions of cooperating individuals. It can be expressed through the innovative potential of individual group members.

$\mathrm{IP}_{\mathrm{PE}}=\mathrm{f}\left(\mathrm{IP}_{\mathrm{II}}, \mathrm{IP}_{\mathrm{I} 2}, \ldots, \mathrm{IP}_{\mathrm{In}}\right)$

where:

$\mathrm{IP}_{\mathrm{PE}}$ innovative potential of people

$\mathrm{IP}_{\mathrm{Ix}}$ innovative potential of $\mathrm{x}$-th individual,

$\mathrm{n}$ number of group members.

Stimulating element in maximizing the above parameters is the effective cooperation. Innovative potential of an individual lies mainly in its openness to adopt new knowledge and willingness to cooperate. Individual is the fountain of good ideas, but needs colleagues for his development and implementation of ideas.

By introducing appropriate forms of work organization (e.g. teamwork) we can achieve even greater increase in the synergistic effect of using the innovative potential of individuals.

\section{b. Innovative potential of organization}

To provide standard operation of the organization requires considerable effort and resources. However, if the organization has to develop, it is necessary to purposefully implement the development activities. To create and maintain an innovative organization is possible if significant support will be given to the use of existing innovative potential of individuals and groups. This means providing information, material and financial resources necessary to achieve the objectives set in relation to the use of the innovative potential of people.

Innovative potential of the organization is a function of all of its available resources. These resources can be divided into four basic groups, while the prerequisite for this process are sufficient funds. Innovative potential of organizations can be, therefore, expressed as follows:

$\mathrm{IP}_{\mathrm{O}}=\mathrm{f}\left(\mathrm{r}_{1}, \mathrm{r}_{2}, \mathrm{r}_{3}, \mathrm{r}_{4}\right)$

while: $z_{1}>0 \wedge z_{2}>\wedge z_{3}>0 \wedge z_{4}>0$

where:

$\mathrm{IP}_{\mathrm{O}}$ innovative potential of organization

$r_{1}$ people $\left(\mathrm{IP}_{\mathrm{P}}-\right.$ innovative potential of people $)$, 
$r_{2}$ information (technology, licenses, patents, trade mark, trade secrets, know-how, codified knowledge,...),

$\mathrm{r}_{3}$ material (tangible assets, technical equipment, materials, energy, ...)

$\mathrm{r}_{4}$ funds

Innovation potential of organization refers to the ability of organization to coordinate the work of individuals, working groups and to develop links in the network of cooperating organizations in order to succeed with customers. To utilize the innovative potential of the organization it is also necessary to ensure the efficient organization and working environment [1].

Neither individual nor group or organization is able to exploit the potential of the knowledge contained in the global business environment by themselves. Wealth of the whole range of disciplines and knowledge potential hidden in the individual organizations cannot be used without networking and fellow innovators [2]. Networking and coordinated cooperation can strengthen the innovative potential of each of the organizations involved.

\section{c. Integrated innovative potential}

It is possible to present an integrated innovative potential through schematic representation of integration of the individual innovative potentials. (Fig. 1)

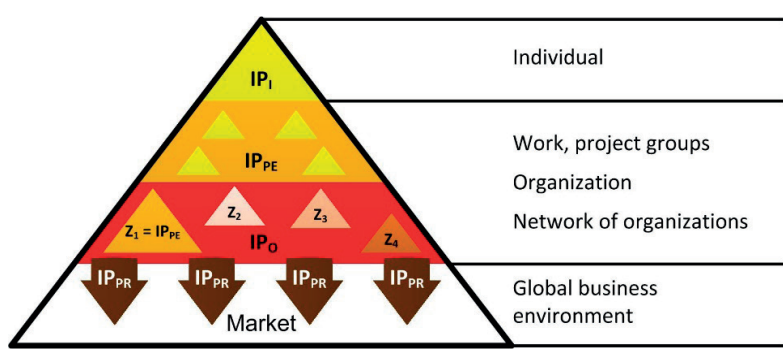

Fig.1. Integrated innovative potential

The individual plays a role of creativity bearer, generating good ideas $\left(\mathrm{IP}_{\mathrm{I}}\right)$. The implementation of the idea generally requires not only resources but also colleagues $\left(\mathrm{IP}_{\mathrm{PE}}\right)$. The organization enables efficient coordination of the work of individuals and groups, securing the necessary tangible and intangible resources $\left(\mathrm{IP}_{\mathrm{O}}\right)$ and active involvement in networks of organizations. The size of the innovation potential of the organization always depends both on the availability of creative individuals willing to cooperate, as well as their ability to actively participate in organization's networks. Given this mechanism, organizations create products based on the new innovation potential $\left(\mathrm{IP}_{\mathrm{PR}}\right)$ and place them on the market within the global business environment.
The pattern of activities (provided below), aimed at efficient use of innovation potentially hidden in people, shows how to purposefully increase innovative potential of the organization.

\section{Creating Innovative Climalite in Organization}

The success of innovations significantly affects innovative environment within the organization. The following findings are formulated as prerequisites and context that must be accepted by all workers engaged in innovation activities and in a process of creating a suitable environment.

At present, it is necessary to work with a large number of activities and knowledge when managing innovations. To better understand the interrelations that have to be accepted in creating innovative environment in the organization, the three dimensional model is designed (Fig. 2). In that model, the first dimension is dedicated to activities during the process of innovating (in relation to the second and third dimension). The process can be divided into the idea generation phase (a) and the solving of innovation projects phase (b). Several supporting activities are ongoing within these stages. The second dimension of the model focuses on activities related to the need to obtain the necessary resources in order to create innovations. These are the human, material (including financial) and information resources. The last and the most problematic dimension focuses on the four basic spheres in which a great potential for the development of innovative solutions is concentrated. The results of the analysis in the area of specific supporting activities (for new innovations) taking place in any organization which can be changed and adjusted have led us to the proposal of four basis spheres. These are:

- Area of Thought - where the philosophy and strategy reflecting the ways of thinking of those focused on future clearly belongs.

- Area of Work (Execution) - consisting especially of processes, work organization, methods and techniques utilized in the work processes.

- Area of Behavior - reflects the ability to develop the intellectual potential, and partnerships in a relatively open business environment.

- Area of Learning by Experience - representing the implementation of knowledge management.

This dimension allows us to specify activities performed by managers that affect thinking, working, behavior and the learning process of organization's employees.

The particular benefit this model offers is that it systemizes activities within the above-mentioned three dimensions. This allows creating specific working conditions required to increase the involvement of workers in innovating. Moreover, the model 
provides a structure that can be continually updated, including in it new activities in the organizations.

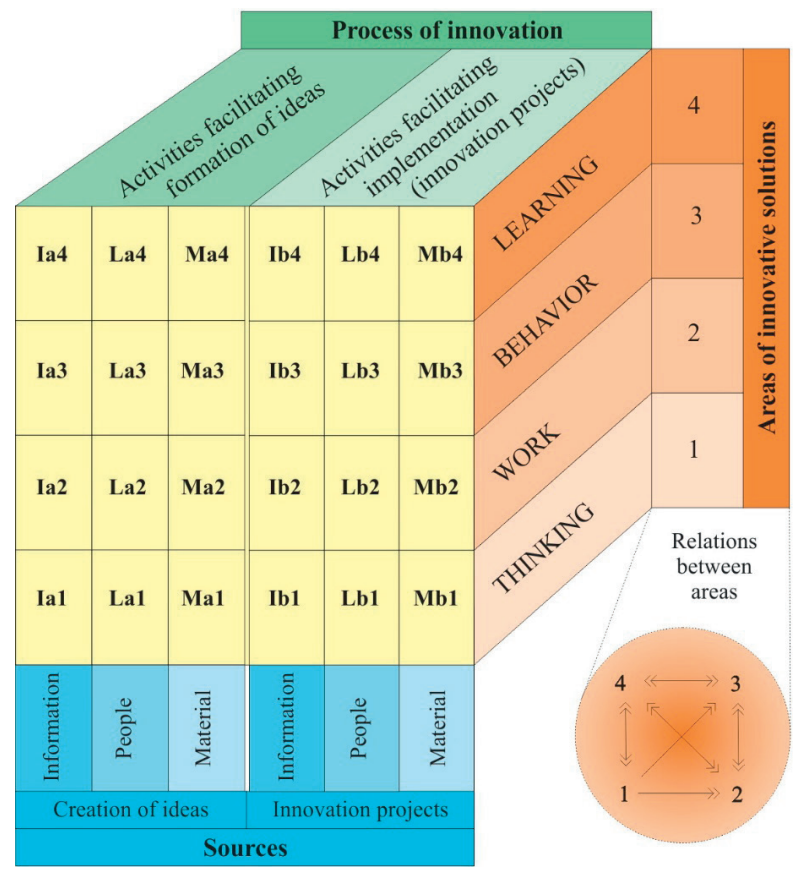

Fig. 2 Activities supporting innovation [3]

In the following sections, individual activities are interpreted, broken down according to the model presented in (Fig. 2) and key notes are formulated to their breakthrough. Their understanding plays a serious role in achieving successful innovative processes.

\subsection{Innovative solutions in the area of thought}

Thinking into the future is one of the pillars of innovation. The area of thought is deciding for the other area, bearing in mind that innovators need to especially master thinking in long term horizons.

a) Promoting stage of generation of ideas

Information (Ia1). Within this area senior management must present the meaning of innovation for the future, use the terminology in the area of innovation and find suitable information channel. It is a way to make the employees interested in engaging in development of something new. If people have a clear idea of what innovation is and how innovation can improve our competitiveness, their thinking will be tuned to capture the stimuli (signaling) changes in both internal and external environments.

Shared vision, understanding of how the company shall evolve through innovation, coupled with genuine support of innovation will be reflected also in activities performed by the innovators. The correct information supports the courage to bear the risk of failure, courage necessary to build self-confidence, the hallmark of innovators.

People (Pa1). Emergence of new ideas can be encouraged when the people will not only be referred to as the most valuable resource of the company, but they will actually be treated as such. If employees acquire new skills and come up with ideas how to use them, it is up to the managers to support them in doing so. The question of motivation and remuneration of employees is also closely related to this topic.

Activities performed by the employees, associated with working with and using new knowledge can be supported also by organizational measures. Sharing knowledge and ideas requires certain psychological readiness to open behavior and willingness to hand over the results of one's work for the benefit of the entire organization.

Organizational and material resources (Ma1). Today, providing material resources and technical equipment for the workplace is usually not a problem [4]. The problem is their efficient use of innovators. A prerequisite for their proper use is that they will be integrated into the existing organizational structures in an organic manner.

If the organizational environment encourages innovation, allows flexible decisions, gives the time and space to study even seemingly unreasonable ideas, enables team work and encourages experimentation, then we can talk about an organizational environment inductive the inception and implementation of innovation [5].

b) Support of stage of delivering innovative projects

Information (Ib1). The manager deciding over initiation of an innovation project must be aware of the fact that:

- There must be a clear link between the innovative project to be implemented and the business strategy.

- He must have enough information on methodologies, techniques and procedures appropriate for the management of innovative projects.

- Addressing innovative projects requires also knowledge of metrics and methods of evaluation of project success.

People (Pb1). The philosophy of managing the company includes finding and utilizing qualified and creative people and involving them in the development of the organization. This approach practically manifests in the fact that company's teams receive flexible goals, offering the responsible people possibility to take decisions in how to solve them. When granted with this freedom, they feel confidence in their abilities and these can be strongly supported by the tools of the knowledge management.

The success of innovative projects may be supported by involving or acquiring workers from other fields or industries. The 
necessary development of the organization's knowledge potential is also supported by the concept of so-called open innovations, the aim of which is to activate the best minds in the external environment in finding solutions to complex problems.

Organizational and material resources (Mb1). Here, the deciding factor is the way the executive managers think and emphasis on the acquisition and allocation of resources. If useful ideas are generated, which however are not applicable within the organization itself, then possibilities of how to use them within partner networks, sell them or protect by industrial patents should be sought.

The system of managing innovation projects must be flexible enough to allow implementation of both small (fast) and large (more time consuming) projects.

\subsection{Innovative solutions in the area of work}

In the area of work we are trying to answer the following question: What can be done now, in the present moment, so that in the future we can let something new appear or discover something new? The work is best organized when there are known and transparent processes. The level of business processes provides well-structured information, which can be used in the phase of generating ideas and also directly during implementation of the innovative projects.

\section{a) Promoting of stage generation of ideas}

Information (Ia2). From the process-oriented point of view, the point here is to secure, preserve and distribute information obtained as well as related ideas that originated in the company. The ability to respond to the innovation stimuli coming from the environment and use them to benefit, requires the organization to have thought-through method of their transmission implemented. For innovators, information is a key resource. It is, therefore, appropriate to establish clear procedures, understandable to everyone in the organization, relating to:

- evaluation of new events and developments of products, technologies and markets,

- creation of knowledge databases,

- use of excellent ideas that do not fit into our business,

- involvement of all departments in the development of new products and processes,

- utilization of techniques for transfer of knowledge from other sectors.

People (Pa2). Preparing people to behave as innovators is among the most important processes and it should be strived to achieve involvement of as many employees as possible. For this reason it is desirable to complement the usual processes of training with activities encouraging the interest of employees in:
- systematic search for new ideas,

- improving relationships with our partners and customers,

- strong involvement in innovative processes.

Organizational and material resources (Ma2). To support the people in generating ideas, it is useful if they have contact with the surrounding environment. Important is to choose the right methods of technical support and appropriate processes of obtaining the necessary resources.

Generating ideas is not stimulated only by the supporting technology. It requires creating personal contacts, visiting scientific meetings, internships and other similar activities.

b) Support of stage of delivering innovative projects

Information (Ib2). If we look at the proven methodologies of innovative project management, we can see that the quality of information obtained in the preparatory phase may decide over the success of the project. Consistent preparation of information and discipline in documenting this information always proves its value in the later phases of the project.

People $(\mathrm{Pb} 2)$. The actual process of delivering an innovative project always depends on the cooperation of team members. The success of the project is significantly dependant on the conviction in the correctness of the procedure, the mutual confidence in abilities of other team members and agreement that the objective of the project is realistic [6].

Experience with innovation projects shows that it is particularly important that the project team himself is convinced that the objectives set are correct.

Organizational and material resources (Mb2). From the organizational point of view, it is important that processes conducive to efficient management of new product development from design to its marketing are in place. This requires a support of methodological expertise. Such methodological background can be provided by internal resources, or can be procured by hiring a specialized consulting firm.

\subsection{Innovative solutions in the area of behavior}

This section focuses on those activities which have not been emphasized in the preceding areas, although they are necessary preconditions for implementation of innovative solutions.

Information ( $\mathrm{Ia} 3, \mathrm{Ib} 3)$. To obtain information possibly leading to exceptional ideas, it is necessary to gain different viewpoints. The easiest way to do so is to use informal connections to people from other professional fields or industries. However, this approach also requires people equipped with knowledge and training in the skill of efficient communication. Similarly, every active link to the research and technological community can 
generate ideas that are not only results of joint efforts, but also offer the possibility to achieve and deepen mutual respect.

People (Pa3, Pb3). Equipping the staff with proper knowledge for innovation is a key issue to address by managers in an innovative organization.

The development of intellectual potential can be achieved by specifically targeted education and training. To specify professional skills and qualification levels of already existing job functions, organizations establish standardized routine processes. The real problem is how to determine what knowledge will be needed in the future.

For that reason, the training of organization's managers should focus on skills of leadership and developing and supporting creativity within the organizations human resources.

Organizational and material resources (Ma3, Mb3). In addition to properly established organizational environment that allows creating and maintaining highly creative teams, sufficient attention needs to be given to remuneration. Even the most gifted and devoted employee is a human whose efforts, ideas and results achieved need to be appreciated.

All our knowledge about motivation will be useful to us, only if we try to understand what actually is for innovators most rewarding way to appreciate their accomplishments.

\subsection{Innovative solutions in the area of learning}

Traversing the proposed model (Fig. 2), we have moved from the level where the basic direction is determined (area of thought), through processes to people and the behavior of innovators - and now we reach the area of learning by experience.

In general, we learn by studying the already available knowledge and performing experiments.

By solving problems, those involved themselves learn in the process and if they are capable of transmitting this experience to others - sharing knowledge takes place.

A part of this learning is a fundamental change or shift in thinking. By learning, people expand their capacity to create.

When in stages of generating ideas and delivering innovation projects, the focus should be on those activities that facilitate development of a learning enterprise.

Information ( $\mathrm{Ia} 4, \mathrm{Ib} 4)$. To gain ideas and overview, it is necessary to look further, beyond the borders of the given field or industry. We try to identify and understand the needs of our customers who can provide us with new insights and inputs for what we are dealing with. Thus, we use the opportunity to learn also from our customers.

It is important to understand that by solving problems, we are also learning. Only then we have the reason to document the lessons learned and reuse them later. Then, we can capture what we have learnt so that it can be also utilized by others in the organization.

People ( $\mathrm{Pa} 4, \mathrm{~Pb} 4)$. Members of the creative teams look for internal benefits in their work. The conviction in meaningfulness of what we do and the ability to look back at the process underwent, allows us to learn from our own experience and consider it a part of the experiments.

If we know that problems stimulate thought, we can consciously acquire habits of creative thinkers. These support our dispositions to utilize knowledge. Although each of us has the potential of creativity inherent, the development of it is tied to work - an active participation in the process of creating new things. Joint work and climate of mutual respect makes it possible to share ideas and enriching one another.

Organizational and material resources (Ma4, Mb4). In the present time we have the opportunity to solve problems and learn not only in the real environment of our organizations, but we can also benefit from virtual working environments [7]. This allows us the use fundamentally new way of exploring options of innovative solutions.

\section{Conclusion}

Organizations are looking for opportunities to increase their efficiency and competitiveness in world markets. Innovations crucially contribute to this. But the problem is how to mobilize organization's performance to support the creation and commercialization of innovative solutions. This paper has focused on this area and presented a possible approach for evaluation of innovative potential of organizations and presented a threedimensional model illustrating the complex linkages in the process of innovating.

The aim of the proposed model was to create a structure of the system supporting innovative environment that is necessary for successful innovation processes in the organization. To create innovative environment, we can certainly use more approaches and processes. The presented model was based on the study of the available innovation theories, presented experience from innovative practice and own knowledge verified in practice.

\section{References}

[1] DULINA, L., BARTANUSOVA, M.: Ergonomics and Preventive Medicine in Companies in Slovak Republic and the EU, Ergonomics 2013, Zagreb : Croatian Ergonomics Society, 2013. 81-86, ISSN 1848-9699. 
[2] STASZEWSKA J.: Marketing Companies (in Poland), Gliwice : Wydawnictwo Politechniky Slaskiej, 2008. p. 148, ISBN: 978-837335-525-5

[3] MICIETA, B., TUREKOVA, H.: Innovation Management: Support for Establishing Innovation (in Slovak), Zilina: GEORG, 2010, p. 184, ISBN 978-80-89478-02-6

[4] MICIETOVA, A., CILLIKOVA, M.: Technology - Machining (in Slovak), Zilina: Zilinska univerzita, 2009, p. 486, ISBN 978-80-5540010-5.

[5] GREGOR, M., MEDVECKY, S.: Zilina University Concept of Digital Factory. Communications - Scientific Letters of the University of Zilina, ISSN 1335-4205, 2008, vol. 10, No. 2, 60-66.

[6] BINASOVA, V.: Management of Manufacturing Organizations in Conditions of Economic Crisis (in Slovak), Advanced Industrial Engineering [CD-ROM]: Monograph of scientific seminar AIE realized at the Department of Industrial Engineering in 2011, 105 123, Zilina: CEIT, 2012, ISBN 978-80-970440-4-6-CD-ROM.

[7] KRAJCOVIC, M. et al.: Intelligent Manufacturing Systems in Concept of Digital Factory, Communications - Scientific Letters of the University of Zilina, ISSN 1335-4205, 2013, vol. 15, No. 2, 77-87. 